\title{
Acute effects of whey protein isolate on blood pressure, vascular function and inflammatory markers in overweight postmenopausal women
}

\author{
Sebely Pal* and Vanessa Ellis \\ School of Public Health, Curtin Health Innovation Research Institute, ATN Centre for Metabolic Fitness, Curtin University of \\ Technology, GPO Box U1987, Perth, WA 6845, Australia
}

(Received 10 May 2010 - Revised 9 September 2010 - Accepted 1 November 2010 - First published online 28 January 2011)

\begin{abstract}
Previous evidence indicates that chronic consumption of dairy whey proteins has beneficial effects on CVD risk factors. The present study investigated the postprandial effects of whey protein isolate on blood pressure, vascular function and inflammatory markers in overweight and obese postmenopausal women. This was a randomised, three-way cross-over design study where twenty overweight and obese postmenopausal women consumed a breakfast meal in conjunction with one of three supplements: $45 \mathrm{~g}$ whey protein isolate, $45 \mathrm{~g}$ sodium caseinate or $45 \mathrm{~g}$ of a glucose control. Fasting and postprandial blood samples, blood pressure and pulse wave analysis readings were taken for up to $6 \mathrm{~h}$. After consumption of the meal, both systolic and diastolic blood pressure, and augmentation index (AI) decreased initially for all interventions and gradually returned to baseline levels by $6 \mathrm{~h}$. However, there were no significant differences in AI, systolic or diastolic blood pressure within or between the glucose control, casein or whey groups. There were also no significant group effects on plasma inflammatory markers (IL-6, TNF- $\alpha$ and C-reactive protein). The health effects previously seen with chronic whey protein ingestion were not seen in the acute $6 \mathrm{~h}$ postprandial period in relation to blood pressure, vascular function or inflammatory markers when compared with casein and a glucose control. This suggests that such effects are better observed from the long-term consumption of whey proteins.
\end{abstract}

Key words: Whey protein: Obesity: Overweight: Postmenopausal women: Postprandial: Blood pressure: Vascular function: Inflammatory markers

CVD is the leading cause of death in industrialised countries such as the USA and Australia ${ }^{(1,2)}$. Risk factors for CVD include hypertension, high blood cholesterol, obesity, poor nutrition and smoking ${ }^{(3)}$. A decrease in blood pressure (BP) of $2-5 \mathrm{mmHg}$ in small populations results in a reduction in total mortality as a result of a lower prevalence of stroke and $\mathrm{CHD}^{(4)}$. Arterial stiffness is an independent risk factor for CVD, particularly atherosclerosis, and its severity may increase with the presence of other CVD risk factors ${ }^{(5,6)}$. Evidence has indicated correlations between arterial stiffness and CVD risk factors such as hypertension, hypercholesterolaemia and obesity $^{(7)}$. Chronic subclinical inflammation is also thought to influence the pathogenesis of atherosclerosis ${ }^{(8)}$. Postmenopausal women are at a particularly high risk of developing CVD, primarily due to the cessation of oestrogen production which occurs during menopause ${ }^{(9,10)}$. Oestrogen confers protection against CVD, as it is a potent stimulator of NO synthase, vascular endothelial growth factor and LDL-receptor activity. The common atherogenic risk profile observed in postmenopausal women includes increased total- and LDL-cholesterol levels, decreased HDL-cholesterol levels, elevated fasting apoB-containing lipoproteins, predominance of small, dense lipoproteins, elevated BP, endothelial dysfunction and insulin resistance ${ }^{(9,10)}$.

Dietary interventions often form part of treatment strategies in dealing with CVD and its associated risk factors such as hypertension and arterial stiffening. Epidemiological studies have shown an inverse relationship between the incidence of stroke and the consumption of milk and milk products ${ }^{(11)}$. The renin-angiotensin system is an important regulator of BP and is often the target of hypotensive medication. Therefore, drugs that inhibit the renin-angiotensin system, either by inhibiting angiotensin-converting enzyme (ACE) or by blocking angiotensin (AT1) receptors, are widely used in the treatment of hypertension ${ }^{(12)}$. Recent evidence also indicates that the administration of ACE inhibitors may also have beneficial effects on inflammatory markers ${ }^{(13,14)}$. Previous evidence indicates that dairy milk proteins inhibit ACE activity ${ }^{(15-18)}$, with in vitro studies suggesting that dairy whey proteins, in particular, have an anti-hypertensive effect ${ }^{(15-17)}$. A study by

Abbreviations: ACE, angiotensin-converting enzyme; AI, augmentation index; AUC, area under the curve; BP, blood pressure; CRP, C-reactive protein; DBP, diastolic blood pressure; SBP, systolic blood pressure.

* Corresponding author: Associate Professor S. Pal, fax +61 89266 2258, email s.pal@curtin.edu.au 
Kawase et al. ${ }^{(16)}$ has shown that systolic blood pressure (SBP) was significantly reduced after ingestion of fermented milk enriched with whey proteins in healthy men after 8 weeks. Interestingly, a recent study by Lee et $a l .{ }^{(19)}$ found that consumption of $125 \mathrm{ml}$ of a milk drink daily which was supplemented with whey peptides, for 12 weeks, did not reduce $\mathrm{BP}$ and/or inflammation markers (IL-6 and C-reactive protein (CRP)) in mildly hypertensive subjects. However, they acknowledge that a higher dose of whey protein may have been required to see a measurable biological effect. A previous study in our laboratory has shown that chronic ingestion of $54 \mathrm{~g}$ of whey/d improved arterial stiffness measures when compared with casein and a glucose control and $54 \mathrm{~g}$ of either whey or casein reduced diastolic blood pressure (DBP) when compared with the control after 12 weeks in overweight and obese participants, suggesting that a higher dose of whey is required for observable effects $^{(20)}$. However, it remains to be elucidated whether the beneficial effects of chronic whey consumption can be observed acutely in the overweight and obese.

Given that chronic consumption of whey proteins can affect $\mathrm{BP}$, arterial stiffness and potentially inflammation, we hypothesise that these pathways would also be affected acutely in overweight and obese postmenopausal women, a population highly susceptible to CVD. Therefore, the aim of the present study was to investigate the postprandial effects of whey protein isolate on BP, vascular function and inflammatory markers compared with casein and glucose supplementation in overweight and obese postmenopausal women.

\section{Methods and procedure}

\section{Subjects}

Healthy, overweight and obese postmenopausal women with a BMI between 25 and $40 \mathrm{~kg} / \mathrm{m}^{2}$, and aged between 40 and 65 years, were recruited from the community. There were a total of 125 respondents, of which seventy-seven respondents were suitable to participate in the study after screening and subsequently commenced the study. Menstrual status was assessed by measured plasma oestradiol levels, with menopause being defined as those with $<10 \mathrm{pg} / \mathrm{ml}$ and amenorrhoea in the previous twelve consecutive months before the study. Exclusion criteria included regular medications (such as lipid lowering and hypotensives) that were likely to affect the study outcomes, hormone replacement therapy, cancer within the last 5 years, smoking, major illnesses, eating disorders, over two standard alcoholic drinks per d, respiratory disease, type 1 or type 2 diabetes and cardiovascular events in the last 6 months. All eligible participants attended a screening visit where measurements of height, weight, waist and hip circumference as well as BP were taken. The present study was conducted according to the guidelines laid down in the Declaration of Helsinki, and all procedures involving human subjects/patients were approved by the Curtin University Human Research Ethics Committee (approval no. HR 131/2007). Written informed consent was obtained from all subjects/patients.

\section{Experimental protocol}

This was a randomised, three-way cross-over design study conducted over 3 weeks, with a 4 -week washout period before commencement. The subjects attended on three separate intervention days, each preceded by a 1-week washout period. All subjects were asked to maintain their usual dietary intake and physical activity levels for the duration of the study. This was monitored by analysing $3 \mathrm{~d}$ weighed food diaries and international physical activity questionnaires ${ }^{(21)}$ that had been completed by the subjects before the commencement of the study and $3 \mathrm{~d}$ before each intervention day. Study subjects refrained from consuming alcohol and caffeine or undertaking any strenuous physical activity for $24 \mathrm{~h}$ before each intervention day and were instructed to consume a standardised evening meal supplied frozen before each visit. On each intervention day, the subjects attended at 08.00 hours at the Health Clinic at Curtin University after a $12-14 \mathrm{~h}$ fast. An indwelling catheter was placed in the antecubital fossa or in a suitable vein in the forearm. Fasting blood samples and measures of BP and augmentation index (AI) were then obtained. Subjects were randomised to consume one of three supplements: $45 \mathrm{~g}$ whey protein isolate, $45 \mathrm{~g}$ sodium caseinate or $45 \mathrm{~g}$ of a glucose control (provided by MG Nutritionals, Brunswick, VIC, Australia) mixed with water and consumed with a breakfast meal. The composition of the protein supplements is shown in Table 1. Subsequent $10 \mathrm{ml}$ of blood samples were then taken at 15, 30, 60, 90, 120, 180, 240 and $360 \mathrm{~min}$, and $\mathrm{BP}$ and $\mathrm{AI}$ readings were taken at 30, 60, 90, 120, 180, 240 and 360 min after consumption of the test meal. Based on our previous experience, greater than $4 \mathrm{~h}$ is required to measure a complete postprandial response of inflammatory markers ${ }^{(22)}$. Subjects remained in the semi-recumbent position during the intervention day and could read, listen to music or do puzzles. They were encouraged to drink water to maintain hydration throughout the day. The catheter was removed after the final blood sample, and the subjects were given something to eat.

\section{Dietary protocol and test meal}

All study subjects were instructed not to take any vitamins or minerals, or other supplements and to minimise dairy intake to 1 serving/d, for 4 weeks leading up to, and during the study period, to limit confounding factors. They were provided with instructions as to what constitutes a serving of dairy. The frozen meal consumed on the evening before each intervention day (McCain's Roast Turkey and Vegetable) contained $1245 \mathrm{~kJ}$, which comprised $26 \%$ protein, $59 \%$ carbohydrates and $15 \%$ fat. The test meal consisted of a $50 \mathrm{~g}$ bread roll with $43 \mathrm{~g}$ of dairy-free, rapeseed margarine and $10 \mathrm{~g}$ of Vegemite or Promite plus whey protein isolate or sodium caseinate supplements or the glucose control (Table 2). All supplements were mixed with $400 \mathrm{ml}$ water and had equal energy content at $875 \mathrm{~kJ}$. The bread roll plus spreads and the supplement were consumed together within $15 \mathrm{~min}$. Subsequent measurements were timed from the subject's completion of the test meal. The supplements were served chilled 
Table 1. Nutrient composition in $50 \mathrm{~g}$ of whey and casein supplements

\begin{tabular}{lcc}
\hline Nutritional information (g) & $\begin{array}{c}\text { Whey protein } \\
\text { isolate }\end{array}$ & $\begin{array}{c}\text { Sodium } \\
\text { caseinate }\end{array}$ \\
\hline Protein (TN $\times 6.38)$ & 44.99 & 45.25 \\
Fat & 0.25 & 0.60 \\
Carbohydrate (lactose) & 0.25 & 0.10 \\
Na & 0.35 & 0.65 \\
Ca & 0.07 & 0.05 \\
P & 0.15 & 0.38 \\
Typical composition (\%) & & \\
Protein & 90.0 & 90.5 \\
Lactose & 0.5 & 0.2 \\
Fat & 0.5 & 1.2 \\
Moisture & 2.2 & 1.3 \\
Ash & 3.7 & 3.8 \\
Sweetener (sucralose) & 0.06 & 0.06 \\
Flavouring & 3.0 & 3.0 \\
Branched-chain amino acid profile (\%, w/w) & \\
Ile & 6.8 & 4.8 \\
Leu & 9.5 & 8.2 \\
Val & 5.8 & 6.0 \\
\hline
\end{tabular}

$\mathrm{TN}$, total $\mathrm{N}$

in dark containers and were matched for appearance, sweetness and palatability with sucralose and flavouring. The total energy content of the complete test meal was $2587 \mathrm{~kJ}$ and fat intake was $45 \%$ of total energy intake. The whey- and casein-supplemented meals contained 38.3\% energy from protein and $16.7 \%$ from carbohydrates, and the glucose-supplemented meal contained $5 \cdot 2 \%$ energy from protein and $49 \cdot 8 \%$ from carbohydrates. Data were analysed using FoodWorks 2007 (Xyris Software, Highgate Hill, QLD, Australia) based on the Australian food composition tables.

\section{Measurement of blood pressure and vascular function}

BP was measured with an automated, calibrated sphygmomanometer (Dinamap, Compact T; Critikon, Norderstedt, Germany ), with subjects in a supine position after resting for at least $10 \mathrm{~min}$. The measurements were taken on the same arm three times at 1 min intervals. These readings were then averaged.

Vascular measurements were performed by using the noninvasive SphygmoCor system (AtCor Medical Private Limited, Sydney, NSW, Australia). This system has been validated in a population at risk of CVD and has been used previously in our laboratory ${ }^{(23-25)}$. The SphygmoCor system produces a pulse wave analysis based on measuring the aortic root pressure waveform via a pen-like device on the peripheral pulse wave, and is represented by the AI. All measurements were performed by the same operator. These measurements were taken three times with a quality index of at least $90 \%$ or over, and the readings were averaged.

\section{Measurement of plasma inflammatory markers}

Blood samples $(10 \mathrm{ml})$ were taken to measure circulating CRP, IL- 6 and TNF- $\alpha$. Serum was isolated by centrifugation at $3000 \mathrm{rpm}$ at $4^{\circ} \mathrm{C}$ for $10 \mathrm{~min}$ and stored at $-80^{\circ} \mathrm{C}$ until the end of the study. Plasma IL- 6, TNF- $\alpha$ and CRP levels were measured by a solid-phase enzyme-amplified sensitivity immunoassay performed on microtitre plates according to the manufacturer's instructions (TNF- $\alpha$ ELISA and IL- 6 ELISA kits: BioSource, Nivelles, Belgium; CRP kits: Alpha Diagnostics International, San Antonio, TX, USA). These are established methods in our laboratory ${ }^{(20,22)}$.

\section{Statistical analysis}

Sample size calculations were based on a minimum predicted $15 \%$ change in area under the curve (AUC) for BP, AI and inflammatory markers between the intervention and control groups, with an expected standard deviation of $15 \%$. A sample size of twenty participants per group was predicted to provide sufficient power $(80 \%)$ to detect significant changes at the 5\% significance level. However, we aimed to recruit twenty-five participants to accommodate for a $20 \%$ attrition rate.

All subjects who completed the study were included in the data analysis. Statistical analysis was conducted using SPSS 17 for Windows (SPSS, Inc., Chicago, IL, USA). Data are expressed as means with their standard errors and assessed for normality. Differences between groups were tested by ANOVA. Postprandial changes in SBP, DBP, AI, TNF- $\alpha$, IL-6 and CRP were tested by ANOVA for repeated measures, taking into account the group and time effect, followed by Tukey's post hoc test. Significant changes for each time point $v$. baseline values were tested by paired $t$ tests. The incremental AUC was determined by subtracting the area below the baseline concentration from the area under the plasma curve between 0 and $6 \mathrm{~h}$. The AUC represents the increase in area following the consumption of a fat load, corrected for fasting concentration. The AUC data were analysed using a general linear model to assess the effects of the groups after adjusting for the following covariates: age and baseline values, with post hoc comparisons made using Tukey's test. An $\alpha$ level of $P<0.05$ was considered statistically significant for all analysis.

This clinical trial has been registered with the Australian New Zealand Clinical Trials Registry. The registration number is ACTRN12609000178246, and the trial web address is http://www.anzctr.org.au/trial_view.aspx?ID=83681

\section{Results}

\section{Subject characteristics}

A total of twenty subjects completed the study, with seven subjects being withdrawn due to unsuitable vein integrity for

Table 2. Nutrient composition of the test meals

\begin{tabular}{lccc}
\hline & Glucose meal & Whey meal & Casein meal \\
\hline Energy (kJ) & 2587 & 2587 & 2587 \\
CHO (g) & 75.3 & 25.3 & 25.3 \\
Protein $(\mathrm{g})$ & 7.9 & 57.9 & 57.9 \\
Fat $(\mathrm{g})$ & 31.2 & 31.2 & 31.2 \\
CHO (\% of energy) & 49.8 & 16.7 & 16.7 \\
Protein (\% of energy) & 5.2 & 38.3 & 38.3 \\
Fat (\% of energy) & 45.0 & 45.0 & 45.0 \\
\hline
\end{tabular}

$\mathrm{CHO}$, carbohydrate. 
Table 3. Baseline subject characteristics

(Mean values with their standard errors, $n$ 20)

\begin{tabular}{lcc}
\hline & \multicolumn{2}{c}{ Subjects } \\
\cline { 2 - 3 } Characteristics & Mean & SEM \\
\hline Age (years) & 57.5 & 1.17 \\
Height (cm) & 164.5 & 1.62 \\
Weight (kg) & 87.2 & 3.49 \\
BMI (kg/m ${ }^{2}$ ) & 32.5 & 1.03 \\
Waist circumference (cm) & 97.2 & 2.65 \\
Hip circumference (cm) & 117.4 & 2.94 \\
Body fat \% (BIA) & 47.1 & 1.25 \\
SBP (mmHg) & 117.70 & 1.92 \\
DBP (mmHg) & 67.69 & 0.09 \\
Augmentation index (\%) & 35.35 & 1.00 \\
Fasting CRP (mg/l) & 0.28 & 0.03 \\
Fasting TNF- $\alpha$ (pg/ml) & 2.62 & 0.13 \\
Fasting IL-6 (pg/ml) & 1.23 & 0.15 \\
\hline BIA, bioelectrical impedance analysis; SBP, systolic \\
$\quad$ blood pressure; DBP, diastolic blood pressure; CRP, \\
C-reactive protein. & \multicolumn{2}{c}{} \\
& \multicolumn{3}{c}{}
\end{tabular}

an indwelling catheter. The results were reported on those that completed the study. Table 3 shows the mean and range of clinical characteristics of the subjects.

\section{Nutritional assessment}

The mean $3 \mathrm{~d}$ dietary intake of subjects before each visit is shown in Table 4. There were no significant differences in energy, fibre and macronutrient intake.

\section{Blood pressure, vascular function and inflammatory markers}

Postprandial SBP, DBP, AI and various inflammatory markers are shown in Fig. 1. There was no significant difference in fasting BP, vascular function or inflammatory markers between the three groups (Fig. 1; Table 5). After consumption of the meal, SBP, DBP and AI decreased initially for all interventions and gradually returned to baseline levels by $6 \mathrm{~h}$ (Fig. 1(a)-(c)). Postprandial SBP, DBP and AI followed a similar pattern for each intervention and were not significantly different between groups at any time point.
The inflammatory marker IL- 6 increased for $6 \mathrm{~h}$ postprandially (Fig. 1(d)), but there was no significant group effect. However, IL-6 was significantly higher than baseline in all three groups at 3, 4 and $6 \mathrm{~h}$ postprandially $(P<0.05)$. There were no significant group effects on plasma TNF- $\alpha$ and CRP concentrations (Fig. 1(e) and (f)). There was also no significant change within groups in TNF- $\alpha$ and CRP concentrations over the $6 \mathrm{~h}$ following the meal.

There was no significant difference in AUC for SBP, DBP or AI between the control, casein or whey groups (Table 6). There was also no difference in AUC for the inflammatory markers IL-6, CRP and TNF- $\alpha$ between the groups.

\section{Discussion}

The present study demonstrated that the ingestion of $45 \mathrm{~g}$ whey protein isolate did not reduce BP, arterial stiffness or inflammatory markers for up to $6 \mathrm{~h}$ postprandially when compared with $45 \mathrm{~g}$ casein and $45 \mathrm{~g}$ of a glucose control in overweight and obese postmenopausal women. The hypotensive effects and improvement in measures of arterial stiffness from whey ingestion observed in previous feeding studies indicate that such effects are observed from intake over a longer time period.

Previous research has demonstrated that milk proteins contain peptides which inhibit ACE activity ${ }^{(15,26)}$, a key enzyme in the regulation of peripheral BP. Casokinins are casein-derived inhibitors of ACE, and lactokinins are whey-derived inhibitors $^{(27)}$. Previous studies in hypertensive rats have indicated that casokinins and lactokinins can significantly reduce $\mathrm{BP}$, with decreases in SBP ranging from 2 to $34 \mathrm{mmHg}^{(28,29)}$. Most of the clinical studies have examined the hypotensive effects of casokinins, with studies showing a reduction of SBP and DBP after consumption of casein and fermented milk $^{(18,30)}$. In addition, a recent study in our laboratory has revealed that consumption of $54 \mathrm{~g}$ whey or $54 \mathrm{~g}$ casein $/ \mathrm{d}$ reduced DBP in overweight individuals after 12 weeks ${ }^{(20)}$. However, there is still uncertainty as to the relative significance of reducing diastolic BP. In contrast, the study by Lee et al. ${ }^{(19)}$ has found that the daily consumption of $125 \mathrm{ml}$ of a milk drink containing whey peptides $(2 \cdot 6 \mathrm{~g})$ over 12 weeks

Table 4. Reported dietary intake data over $3 d$ before each intervention day as assessed by weighed food records*

(Mean values with their standard errors)

\begin{tabular}{|c|c|c|c|c|c|c|}
\hline & \multicolumn{2}{|c|}{ Control (glucose) } & \multicolumn{2}{|c|}{ Casein } & \multicolumn{2}{|c|}{ Whey } \\
\hline & Mean & SEM & Mean & SEM & Mean & SEM \\
\hline Energy (kJ) & 6673 & 287 & 6445 & 314 & 6537 & 346 \\
\hline Carbohydrate (\% of total energy) & $46 \cdot 8$ & $2 \cdot 1$ & $46 \cdot 2$ & $2 \cdot 3$ & $45 \cdot 4$ & $1 \cdot 8$ \\
\hline Protein (\% of total energy) & $19 \cdot 3$ & $1 \cdot 1$ & $20 \cdot 0$ & 0.4 & $19 \cdot 1$ & $1 \cdot 3$ \\
\hline Total fat (\% of total energy) & $32 \cdot 6$ & $2 \cdot 1$ & $32 \cdot 3$ & $2 \cdot 6$ & $32 \cdot 3$ & $1 \cdot 7$ \\
\hline Saturated fat (\% of total energy) & $37 \cdot 2$ & $1 \cdot 8$ & $39 \cdot 2$ & $1 \cdot 8$ & $36 \cdot 9$ & $2 \cdot 2$ \\
\hline Monounsaturated fat ( $\%$ of total energy) & $43 \cdot 2$ & 1.4 & $40 \cdot 9$ & 1.4 & $41 \cdot 1$ & $1 \cdot 7$ \\
\hline Polyunsaturated fat ( $\%$ of total energy) & $19 \cdot 8$ & 1.5 & $19 \cdot 3$ & 1.6 & $20 \cdot 6$ & $1 \cdot 5$ \\
\hline $\mathrm{Ca}(\mathrm{mg})$ & 447 & 42 & 457 & 41 & 461 & 49 \\
\hline Fibre $(g)$ & $17 \cdot 8$ & $1 \cdot 2$ & $18 \cdot 2$ & $1 \cdot 3$ & $17 \cdot 5$ & 1.4 \\
\hline
\end{tabular}

* There was no significant difference in dietary intake before each postprandial visit. 

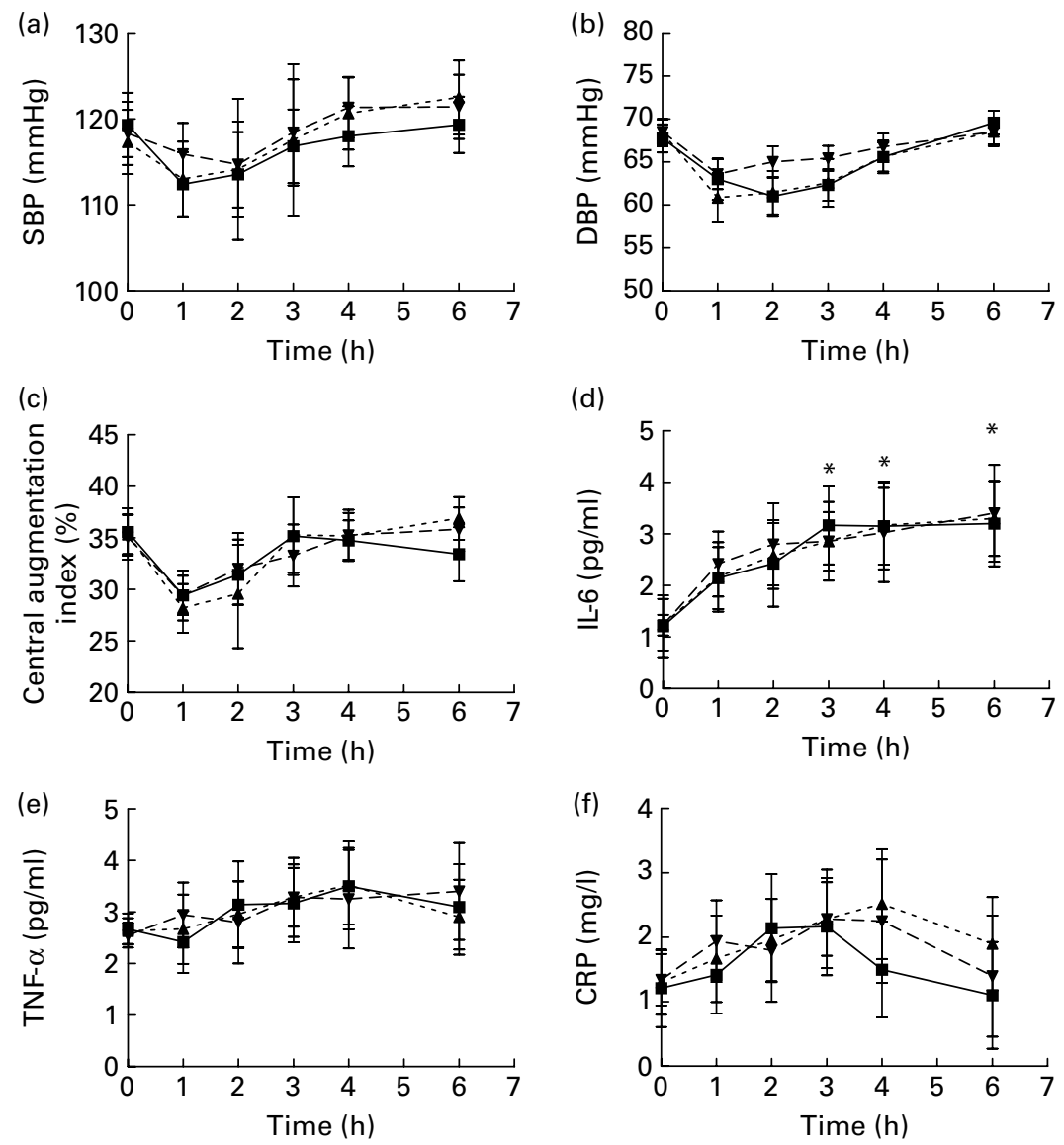

Fig. 1. Mean (a) Systolic blood pressure (SBP), (b) diastolic blood pressure (DBP), (c) augmentation index, (d) IL-6, (e) TNF- $\alpha$ and (f) C-reactive protein (CRP) levels for the control, casein and whey groups at baseline and during the $6 \mathrm{~h}$ following consumption of the meal. Values are means, with standard errors represented by vertical bars. * Means values of all intervention groups were significantly different from baseline $(P<0 \cdot 05)$. $\longrightarrow-$ Control; $--\AA--$, casein; $-\rightarrow--$, whey.

did not reduce BP compared with a lactose control drink, suggesting that higher doses as used in our previous studies are required to observe $\mathrm{BP}$ reductions. They have proposed that the lack of an in vivo effect could be due to the degradation of the peptides by intestinal or plasma peptidases before they could exert an effect on BP or there was an insufficient reabsorption of the peptides in the milk drink. However, they have suggested that a greater dose of whey may have been required to exert a observed biological effect $^{(19)}$. Despite the previous evidence indicating the hypotensive effects of whey and casein in our laboratory ${ }^{(20)}$, there were no changes in BP postprandially over $6 \mathrm{~h}$ after consuming whey and casein when compared with a glucose control in the present study, even with a high dose of $45 \mathrm{~g}$. This may indicate that the effect of whey on BP may need to be undertaken over a longer period of time to see any effect and that a one-off dose of whey protein is inadequate to regulate or inhibit ACE activity.

Arterial stiffening is an independent risk factor for CVD ${ }^{(31)}$ and is associated with ageing, as the central arteries gradually stiffen over time ${ }^{(32)}$. The rate of progression is influenced by hypertension, diabetes and atherosclerosis ${ }^{(33)}$. Arterial stiffness

Table 5. Fasting blood and vascular measurements in each group (Mean values with their standard errors)

\begin{tabular}{|c|c|c|c|c|c|c|}
\hline & \multicolumn{2}{|c|}{ Control } & \multicolumn{2}{|c|}{ Casein } & \multicolumn{2}{|c|}{ Whey } \\
\hline & Mean & SEM & Mean & SEM & Mean & SEM \\
\hline Fasting TNF (pg/ml) & 2.67 & 0.23 & $2 \cdot 63$ & 0.24 & $2 \cdot 55$ & 0.23 \\
\hline Fasting IL-6 (pg/ml) & $1 \cdot 21$ & 0.13 & $1 \cdot 24$ & 0.15 & $1 \cdot 23$ & 0.12 \\
\hline CRP (mg/l) & $1 \cdot 21$ & 0.13 & $1 \cdot 30$ & 0.16 & $1 \cdot 34$ & 0.18 \\
\hline $\mathrm{SBP}(\mathrm{mmHg})$ & $119 \cdot 32$ & 3.91 & $117 \cdot 32$ & $3 \cdot 14$ & $118 \cdot 34$ & 3.45 \\
\hline $\mathrm{DBP}(\mathrm{mmHg})$ & $68 \cdot 40$ & 1.89 & $67 \cdot 08$ & $1 \cdot 16$ & 68.94 & 1.76 \\
\hline Augmentation index (\%) & 35.05 & 1.79 & 35.42 & $1 \cdot 72$ & $35 \cdot 30$ & $2 \cdot 14$ \\
\hline
\end{tabular}

CRP, C-reactive protein; SBP, systolic blood pressure; DBP, diastolic blood pressure. 
Table 6. Effect of the test meal on postprandial blood pressure, vascular function and inflammatory markers

(Mean values with their standard errors)

\begin{tabular}{|c|c|c|c|c|c|c|}
\hline \multirow[b]{2}{*}{ Area under the curve* } & \multicolumn{2}{|c|}{ Control } & \multicolumn{2}{|c|}{ Casein } & \multicolumn{2}{|c|}{ Whey } \\
\hline & Mean & SEM & Mean & SEM & Mean & SEM \\
\hline $\mathrm{SBP}(\mathrm{mmHg})$ & 703.47 & 14.41 & $704 \cdot 15$ & $14 \cdot 39$ & $706 \cdot 47$ & 14.05 \\
\hline $\mathrm{DBP}(\mathrm{mmHg})$ & 389.67 & $6 \cdot 24$ & 388.37 & $6 \cdot 24$ & $389 \cdot 15$ & $6 \cdot 11$ \\
\hline Augmentation index (\%) & $180 \cdot 33$ & 5.73 & $172 \cdot 32$ & 5.73 & $175 \cdot 1$ & $5 \cdot 71$ \\
\hline CRP (mg/l) & 14.5 & $2 \cdot 47$ & $17 \cdot 34$ & $2 \cdot 01$ & 19.94 & 2.04 \\
\hline IL-6 (pg/ml) & $116 \cdot 70$ & $12 \cdot 47$ & $126 \cdot 50$ & $12 \cdot 47$ & 123.40 & 12.47 \\
\hline TNF- $\alpha(\mathrm{pg} / \mathrm{ml})$ & $22 \cdot 25$ & 3.08 & $16 \cdot 49$ & 3.09 & 18.51 & 3.09 \\
\hline
\end{tabular}

can be assessed using pulse wave analysis, a non-invasive method that indirectly measures arterial stiffness using radial applanation tonometry ${ }^{(7)}$. This is represented by the AI. It has been proposed that an increase in arterial stiffening may be associated with increases in SBP and $\mathrm{DBP}^{(7,34-36)}$. While mechanisms of age- and disease-related arterial stiffness are not fully understood, previous studies have indicated that components of the renin-angiotensin system, matrix metalloproteinases, intracellular signalling and extracellular matrix components may be involved in the process ${ }^{(7,34-36)}$. Given the potential effects of dairy protein on the angiotensin system $^{(28-30,37)}$, it could be expected that dairy proteins may also have a beneficial effect on AI. A previous study in our laboratory found that supplementation with $54 \mathrm{~g}$ of whey protein a day for 12 weeks resulted in a $21 \%$ decrease in AI compared with the control group and a $23 \%$ decrease when compared with the casein group in overweight and obese individuals ${ }^{(20)}$. The mechanism for the effect of whey on AI was not known, but it was proposed that differences between whey and casein digestion and absorption may provide an insight. Whey protein consists of a heterogeneous group of proteins containing lactalbumin, $\beta$-lactoglobulin, immunoglobulins and lactoperoxidase. Whey generally also has a higher content of branched-chain amino acids (such as leucine, isoleucine and valine) when compared with casein, which is thought to be responsible for its efficient metabolism after consumption ${ }^{(38)}$. However, the valine content was similar in both whey and casein supplements used in the present study. Whey has been shown to have a fast rate of digestion and absorption when compared with casein, which is a coagulating protein that slows gastric emptying ${ }^{(39)}$. Due to the rapid emptying of whey by the stomach, it arrives at the small intestine intact, enabling it to participate in a number of bioactivities in both the gut and circulation ${ }^{(39)}$. As a result, the postprandial appearance of plasma amino acids is much higher after whey consumption when compared with casein ${ }^{(39)}$. The greater content of amino acids, in particular branched-chain amino acids, after whey consumption, and peptide fractions or the synergistic actions between them, may explain the physiological effects of whey. In the present acute study, however, there was no decrease in AI postprandially after consumption of whey when compared with casein and control. This may indicate that consumption of whey would need to be prolonged to see a reduction in $\mathrm{AI}$ and therefore arterial stiffening. In our previous feeding study, a significant reduction in AI was only observed after 12 weeks of whey consumption but not after 6 weeks ${ }^{(20)}$. In contrast to the present study, Ballard et al. ${ }^{(40)}$ found that consumption of $5 \mathrm{~g} / \mathrm{d}$ of a novel whey-derived peptide (NOP-47) after 2 weeks resulted in no change in vascular function in healthy individuals; interestingly, however, $5 \mathrm{~g}$ of the whey-derived peptide improved vascular function postprandially when compared with a placebo. They suggested that ACE-inhibitory activity of the novel whey peptide may have been responsible, as previous clinical trials had shown that patients taking ACE inhibitors had resulted in improvements in vascular function ${ }^{(40)}$. The effects of whey protein components such as novel wheyderived peptides should be further investigated in both the longer feeding and acute settings.

Chronic inflammation is thought to play an important role in the pathogenesis of atherosclerosis ${ }^{(41)}$. We have previously demonstrated that the type of fat in a meal can regulate the concentration of inflammatory cytokines, CRP, TNF- $\alpha$ and IL-6 postprandially ${ }^{(22)}$. It has been shown that ACE inhibitors can have beneficial effects on inflammatory markers ${ }^{(13,14)}$, CRP, IL- 6 and TNF- $\alpha$, so the potential ACE-inhibitory activity of dairy proteins was investigated postprandially. The present study revealed that CRP, IL- 6 and TNF- $\alpha$ levels were not influenced by whey or casein supplementation postprandially. These findings are consistent with previous feeding studies examining whey and milk peptides on inflammatory markers $^{(16,20,40)}$.

It is possible that the lack of the effect of whey protein in the present study on BP, vascular function or inflammatory markers may be related to the confounding effects of the test meal. Consuming a test meal with the supplements may have slowed down gastric emptying, which could have delayed or inactivated bioactive components once they reached the small intestine. This may have attenuated the beneficial effects of whey on BP and vascular function in the present study. Future research could investigate these effects after consumption of the supplements only, thereby limiting possible confounding effects from the meal.

In conclusion, the present study demonstrated that consumption of $45 \mathrm{~g}$ whey protein isolate did not alter BP, vascular function or inflammatory markers in a $6 \mathrm{~h}$ postprandial 
period when compared with casein and a glucose control in overweight and obese postmenopausal women. It is difficult to speculate whether the same effects would have been observed in men of the same BMI. These trials need to be conducted in future studies. Previous feeding studies have demonstrated the hypotensive effects of whey and casein and improvements in arterial stiffness after whey consumption, suggesting that intake over a longer time is required. However, the potential of whey in improving CVD risk factors such as BP and arterial stiffness should be investigated further, exploring the effects of whey postprandially with higher doses of whey than the $45 \mathrm{~g}$ used in the present study. Further investigations into novel whey peptides or studies in a population group that is hypertensive are also recommended. Thus, there is a need for future research investigating the potential benefits of both acute and chronic whey protein ingestion on metabolic risk factors.

\section{Acknowledgements}

The present study is a Dairy Australia initiative funded by the Dairy Service Levy and the Australian Government. Partial support was also provided by the ATN Centre for Metabolic Fitness (Bentley, WA, Australia). We thank Murray Goulburn Nutritionals (Brunswick, VIC, Australia) for providing the supplements. The authors' responsibilities were as follows: V. E. coordinated the trial, data collection and input into the manuscript. S. P. conceived and designed the study, wrote the manuscript, supervised the study and conducted the statistical analysis. The authors had no conflict of interest in relation to the work reported in the present study.

\section{References}

1. Kochanek K, Murphy S, Anderson R, et al. (2004) Deaths: final data for 2002. Natl Vital Stat Rep 53, 1-115.

2. Australian Bureau of Statistics (2009) Causes of Death, Australia 2007. Canberra, ACT: ABS Publication. http:// www.abs.gov.au/ausstats/abs@.nsf/Products/9982A795F3C1 3BE2CA25757C001EF4D9?opendocument (updated 22 January 2010).

3. Australian Bureau of Statistics (2006) Cardiovascular Disease in Australia: A Snapshot, 2004-05. Canberra, ACT: ABS Publication. http://www.abs.gov.au/ausstats/abs@.nsf/mf/ 4821.0.55.001 (updated 22 January 2010).

4. Appel L, Brands M, Daniels S, et al. (2006) Dietary approaches to prevent and treat hypertension. A scientific statement from the American Heart Association. Hypertension 47, 296-308.

5. van Trijp M, Bos W, Uiterwaal C, et al. (2004) Determinants of augmentation index in young men: the ARYA study. Eur J Clin Invest. 34, 825-830.

6. Wilkinson I \& McEniery C (2004) Arterial stiffness, endothelial function and novel pharmacological approaches. Clin Exp Pharmacol Physiol 31, 795-799.

7. Schiffrin E (2004) Vascular stiffening and arterial compliance: implications for systolic blood pressure. Am J Hypertens 17, 39S-48S

8. Ross R (1999) Atherosclerosis - an inflammatory disease. $N$ Engl J Med 340, 115-126.
9. Gaspard U, Gottal J \& van den Brule F (1995) Postmenopausal changes of lipid and glucose metabolism: a review of their main aspects. Maturitas 21, 171-178.

10. Bechlioulis A, Naka K, Papanikolaou O, et al. (2009) Menopause and hormone therapy: from vascular endothelial function to cardiovascular disease. Hellenic J Cardiol 50, $303-315$.

11. Abbott R, Curb J \& Rodriguez B (1996) Effect of dietary calcium and milk consumption on the risk of thrombolic stroke in older middle-aged men. The Honolulu Heart Program. Stroke 27, 813-818.

12. Doulton T (2006) ACE inhibitor-angiotensin receptor blocker combinations: a clinician's perspective. Mini Rev Med Chem 6, 491-497.

13. Prasad K (2006) C-reeactive protein (CRP)-lowering agents. Cardiovasc Drug Rev 24, 33-50.

14. Andrzejczak D, Górska D \& Czarnecka E (2007) Influence of enalapril, quinapril and losartan on lipopolysaccharide (LPS)-induced serum concentrations of TNF-alpha, IL-1 beta, IL-6 in spontaneously hypertensive rats (SHR). Pharmacol Rep 59, 437-446.

15. FitzGerald R \& Meisel H (1999) Lactokinins: whey proteinderived ACE inhibitory peptides. Nabrung 3, 165-167.

16. Kawase M, Hashimoto H, Hosoda M, et al. (2000) Effect of administration of fermented milk containing whey protein concentrate to rats and healthy men on serum lipids and blood pressure. J Dairy Sci 83, 255-263.

17. Mullaly M, Meisel H \& FitzGerald R (1997) AngiotensinI-converting enzyme inhibitory activities of gastric and pancreatic proteinase digest of whey proteins. Int Dairy 7 , 299-303.

18. Seppo L, Jauhiainen T, Poussa T, et al. (2003) A fermented milk high in bioactive peptides has a blood pressurelowering effect in hypertensive subjects. Am J Clin Nutr 77, 326-330.

19. Lee Y, Skurk T, Hennig M, et al. (2007) Effect of a milk drink supplemented with whey peptides on blood pressure in patients with mild hypertension. Eur J Nutr 46, 21-27.

20. Pal S \& Ellis V (2009) The chronic effects of whey proteins on blood pressure, vascular function and inflammatory markers in overweight individuals. Obesity 18, 1354-1359.

21. Craig C, Marshall A, Sjöström M, et al. (2003) International physical activity questionnaire: 12-country reliability and validity. Med Sci Sports Exerc 35, 1381-1395.

22. Arya F, Egger S, Colquhoun D, et al. (2010) Differences in postprandial inflammatory responses to a 'modern' v. traditional meat meal: a preliminary study. $\mathrm{Br} J$ Nutr 104, 724-728.

23. Janner J, Godtfredsen N, Ladelund S, et al. (2010) Aortic augmentation index: reference values in a large unselected population by means of the SphygmoCor device. Am J Hypertens 23, 180-185.

24. van Trijp M, Bos W, van der Schouw Y, et al. (2005) Alcohol and arterial wave reflections in middle aged and elderly men. Eur J Clin Invest 35, 615-621.

25. Naissides M, Mamo J, James T, et al. (2006) The effect of chronic consumption of red wine polyphenols on vascular function in postmenopausal women. Eur J Clin Nutr 60, $740-745$.

26. Takano T (1998) Milk derived peptides and hypertension reduction. Int Dairy J 8, 375-381.

27. FitzGerald R \& Meisel H (2000) Milk protein-derived peptide inhibitors of angiotensin-I-converting enzyme. Br J Nutr 84 , S33-S37.

28. Abubakar A, Tadao S, Kitazawa H, et al. (1998) Structural analysis of new antihypertensive peptides derived from 
cheese whey protein by proteinase K digestion. J Dairy Sci 81, 3131-3138.

29. Nurminen M, Sipola M, Kaarto H, et al. (2000) Lactorphin lowers blood pressure measured by radiotelemetry in normotensive and spontaneously hypertensive rats. Life Sci 66, 535-543.

30. Hata Y, Yamamoto M, Ohni M, et al. (1996) A study on the effect of sour milk on blood pressure in hypertensive patients. Am J Clin Nutr 64, 767-771.

31. Qureshi G, Brown R, Salciccioli L, et al. (2007) Relationship between aortic atherosclerosis and non-invasive measures of arterial stiffness. Atherosclerosis 195, e190-e194.

32. Greenwald S (2007) Ageing of the conduit arteries. J Pathol 211, $157-172$.

33. Benetos A, Waeber B, Izzo J, et al. (2002) Influence of age, risk factors and cardiovascular and renal disease on arterial stiffness: clinical applications. Am J Hypertens $\mathbf{1 5}$, 1101-1108.

34. Blacher J \& Safar M (2005) Large-artery stiffness, hypertension and cardiovascular risk in older patients. Nat Clin Pract Cardiovasc Med 2, 450-455.

35. Safar M (2001) Systolic blood pressure, pulse pressure and arterial stiffness as cardiovascular risk factors. Curr Opin Nephrol Hypertens 10, 257-261.
36. Tomiyama H, Hashimoto H, Hirayama Y, et al. (2006) Synergistic acceleration of arterial stiffening in the presence of raised blood pressure and raised plasma glucose. Hypertension 47, 180-188.

37. Sekiya S, Kobayashi Y, Kita E, et al. (1992) Antihypertensive effects of tryptic hydrolysate of casein on normotensive and hypertensive volunteers (in Japanese). J Jap Soc Nutr Food Sci 45, 513-517.

38. Bastian E \& Harper W (2003) Emerging health benefits of whey. Dairy Council Digest 74, 31-36.

39. Boirie Y, Dangin M, Gachon P, et al. (1997) Slow and fast dietary proteins differently modulate postprandial protein accretion. Proc Natl Acad Sci U S A 94, 14930-14935.

40. Ballard K, Bruno R, Seip R, et al. (2009) Acute ingestion of a novel whey-derived peptide improves vascular endothelial responses in healthy individuals: a randomized, placebo controlled trial. Nutr J 8, 34 .

41. Humbert M, Monti G, Brenot F, et al. (1995) Increased interleukin-1 and interleukin-6 serum concentrations in severe primary pulmonary hypertension. Am J Respir Crit Care Med 151, 1628-1631. 